\title{
Post-Digital World, Pandemic and Higher Education
}

\author{
Alexander Sergeevich Safonov ${ }^{1} \&$ Anastasia Vladimirovna Mayakovskaya ${ }^{2}$ \\ ${ }^{1}$ Department of Social Philosophy, Institute of Social and Philosophical Sciences and Mass Communications, Kazan \\ Federal University, Russia \\ ${ }^{2}$ Department of General and Ethnic Sociology, Institute of Social and Philosophical Sciences and Mass \\ Communications, Kazan Federal University, Russia \\ Correspondence: Alexander Sergeevich Safonov, Department of Social Philosophy, Institute of Social and \\ Philosophical Sciences and Mass Communications, Kazan Federal University, Russia. E-mail: \\ chelovek-3000@yandex.ru
}

Received: September 9, 2020

Accepted: October 21, 2020

Online Published: October 31, 2020

doi:10.5430/ijhe.v9n8p90

URL: https://doi.org/10.5430/ijhe.v9n8p90

\begin{abstract}
The article examines the prospects that open up for the implementation of the educational process in higher educational institutions, as well as the problems faced by the modern higher education system in the context of the transition to distance learning caused by the current epidemiological situation in the post-digital world. On the basis of the data from a student survey made during the COVID-19 pandemic, who studied using distance digital technologies, we have analyzed the current state of higher education. Consequently, the authors have concluded that the universities, implementing programs for the digitalization of the educational process and the creation of massive online courses, are actually away from the real social circles of the post-digital society. Given the results, the authors argue that digitalization is not a way to resolve the internal contradictions of higher education. Moreover, digitalization as a goal of higher education somewhat hides the real contradictions of the learning process.
\end{abstract}

Keywords: Post-digital, digitalization, higher education, online education, pandemic, COVID-19

\section{Introduction}

In 2016, Klaus Shwab, speaking at the World Economic Forum in Davos, voiced the idea that humanity is undergoing unprecedented technological, economic and social transformations. The changes that are taking place represent a boundary, passing which, civilization will enter a fundamentally new era of its historical development. Shwab gives the generic name of the Fourth Technological Revolution for this new era. From his point of view, the First Revolution was caused by the beginning of production mechanization with the help of steam engines, the Second used the energy of electricity to create a mass product, and the Third became the electronic information era of the automation of production processes. The main feature of the new technological revolution is the rapid digitalization, blurring the boundaries between biological and cybernetic: "Now a Fourth Industrial Revolution is building on the Third, the digital revolution that has been occurring since the middle of the last century. It is characterized by a fusion of technologies that is blurring the lines between the physical, digital, and biological spheres" (Schwab, 2016).

It is worth mentioning that the planned developments in modern reality, under the general name of the Fourth Technological Revolution, should not be considered as a one-time phenomenon. Digital transformation is a time-expanded process. The very possibility of conceptualizing the challenges of a new era proves the fact that digital technologies have already become a part of social reality. Moreover, it is more accurate to describe modernity with the term post-digital, which: on the one hand, fixes digitalization as an implemented and a developing phenomenon; on the other hand, as a phenomenon that changes social reality. This term is broadly applied in many studies (Jandrić et al., 2018). Florian Cremer defines the term "post-digital", indicating its similar formation with the concepts of "post-feminism", "post-punk", "post-apocalypse", etc.: "None of these terms - post-punk, post-communism, post-feminism, postcolonialism, post-apocalyptic - can be understood in a purely Hegelian sense of an inevitable linear progression of cultural and intellectual history. Rather, they express more subtle cultural shifts 
and ongoing mutations" (Cramer, 2015). The prefix "post" in this case indicates not a new era, which is the overcoming and rejection of something obsolete, however a period of ongoing social and cultural transformations led by some significant phenomenon. Hence, we can state that the term "digital" can only be applied to technologies ("digital camera", "digital media", etc.). At the same time, "post-digital" captures social phenomena existing in the context of the emergence and mass distribution of digital technologies: "In this sense, the post-digital condition is a post-apocalyptic one: the state of affairs after the initial upheaval stemmed from the computerization and global digital networking of communication, technical infrastructures, markets and geopolitics" (Cramer, 2015).

\section{Methods}

Methods: As an empirical base, we used data from a survey conducted among students of Russian federal universities. The analysis used the answers of 2,560 respondents who answered the following question "What problems and difficulties did you face when switching to forced temporary distance learning at the university?". After analyzing the data obtained during our study, we identified the systemic difficulties that the respondents faced within the transition to distance learning.

\section{Results and Discussion}

Digitalization is viewed not as a general trend and an endpoint of development, towards which all social spheres are directed, but as a phenomenon with which all social spheres enter into relations. At the same time, different spheres have different relationships with digitalization and are not always unambiguous. Thus, if we take higher education, it can be noted that a modern university is experiencing an active digitalization of the educational process. Most universities in the world are developing massive online courses (MOOC's), which can be regarded as a way to the future digital education, in which the student is an active user who independently determines the curriculum, time and place of his/her study. Since its occurrence, digital technologies in education have quickly turned for the universities into a specific area of business that actively attracts investors. Andrew Stachiw notes this rapid transformation of MOOC's from free educational technology into a promising business project for many universities: "MOOCs are relatively new, yet they have taken the field of education by storm. In 2002, MIT launched OpenCourseWare, aiming to make all of its course materials free and online. <..> Most recently, Edx, a project of MIT, Harvard and Berkeley, and a growing list of universities are offering courses from their professors that are open to literally thousands of people per course offering. Similar to the privatization of public schools, MOOCs have become big business, often driven by venture capitalists" (Stachiw, 2014; Octaberlina \& Muslimin, 2020). This state of affairs is regarded as a prospect for the development of higher education; digital technologies are seen as a means for creating a qualitatively new effective way of teaching. Thus, the universities in the "post-digital" world, on the one hand, tend to regard digital modernity as a promising way to make higher education free from internal contradictions and shortcomings.

One of the main educational problems, which may be solved by digitalization and MOOC's, is an outdated form of traditional education. This type of teaching presupposes a teacher's domineering figure, transferring some knowledge to the passively perceiving students. The disadvantages of this approach are obvious; the students should not only memorize information and reproduce it at the domineering teacher's request but learn to use the knowledge gained actively. For students, knowledge should be the basis of their productive activity; they should be able to do something with the bulk of information that they receive in the classrooms. Therefore, modern educational approaches are moving towards reducing the teacher's domineering role and motivating students to show personal activity. The teacher turns from a teaching dictator into a mediator who only organizes the learning process of students. G. Biesta argues that this understanding of the reformation approach to teaching is seen almost as a self-evident alternative to the traditional approach: "This seems to suggest that the only progressive alternative lies in the demise of the teacher - and more precisely the demise of "traditional" teaching — and a turn towards learning; a turn where the teacher only exists as a facilitator of otherwise "autonomous" learning processes" (Biesta, 2016).

It seems that the post-digital world is ideal for implementing a progressive approach to learning. Due to digital technology, the students are not tied to either place or time of their study. They are able to personalize the learning process as much as possible, choosing the pace and depth of immersion in teaching materials that suit them. A student who learns with the help of digital technologies becomes a full-fledged actor of his/her own education. And the university creates the most flexible and efficient digital environment suitable for the implementation of his/her goals. Digital learning fits almost perfectly into the notion of modern learning: "The MOOCs revolution promises to 
open up school-level and higher education by providing accessible, flexible, affordable courses, using a range of platforms. < ..> Open education brings opportunities for innovation and exploration of new learning models and practices" (Peters, 2017; Saser \& Makhasane, 2020).

Given the fact that higher education, existing in the post-digital reality and actively introducing the digital technologies into the educational process, still considers digitalization as a future panacea for deep-seated shortcomings, it can be noted that the present and future time plan is paradoxically mixed for the education in digital technologies. We can say that higher education perceives the current post-digital present as its own future. The universities are in an illusory disconnection from reality by consoling themselves with the hope of a bright digital future, although there is much evidence that digital technologies have not led to a qualitative evolution now. For example, P. Murphy, examining the conditions for creative research at a modern university, notes: "All of this begs the question then: what drives intellectual production? The answer is certainly not "the Internet'" (Murphy, 2013). Digital technologies only hide the old problems of higher education and seem to be the technology of the future. However, it is obvious that the existing shortcomings will simply be transferred to the digital environment. The new digital education will simply inherit the genetic flaws of analogue education.

The management of Russian universities has been puzzled by the issues of introducing online learning into higher education over the past few years. This process is being developed rapidly at such leading universities as Moscow State University, Higher School of Economics, St. Petersburg State University, and these higher educational institutions have several hundred online courses that are used not only in Russia but also abroad. Although regional universities are just beginning to digitalize education, the situation that has developed in connection with the quarantine forced to accelerate the introduction of distance digital forms into the educational process. Even though the universities are faced with the need for a rapid transition to distance learning, this process, according to experts in the education system, was successful. The rector of the Higher School of Economics, Yaroslav Kuzminov, notes that "...distance learning is successful to a greater extent in the country and Russian universities coped well with the quarantine" (Kuzmina, 2020).

This can also be explained by the fact that the COVID-19 pandemic took place in the post-digital world. In many ways, the fact that the university switched to distance learning forms without significant difficulties is due to the technological development of digital technologies in the modern world. The overwhelming majority of $85.3 \%$ of respondents answered in the affirmative to the question: "Are you satisfied with the organization of the educational process in the situation of distance learning on the whole?" Among them, 43.8\% of respondents answered "completely satisfied with the organization of distance learning", and $41.5 \%$ - "rather satisfied, but with some reservations". In the pre-digital world, the organization of distance learning in such a short time would hardly have been possible at all just 20 years ago. However, the transition to distance learning has generally been successful in today's post-digital world, in which every student and teacher is already integrated into the digital environment.

The tendency to view digital technologies as a saving future, capable of making a qualitative change in the learning process for the better, should be understood as a refusal to face reality and admit that the digital future has already arrived and that it cannot be the basis of a new education paradigm. Digital technology in the post-digital world has long been a common element of everyday life. A modern person, regardless of his/her age, is integrated into digital reality. The smartphone is no longer perceived as a technological miracle; it is an element of everyday post-digital reality. Therefore, digital education and digital university are not a new pedagogy and not a way to save learning from internal contradictions; this is the reality in which higher education already exists: "The digital university is not a place, technology, or way of thinking. The digital university is simply what teachers and students do in the digital age" (Peters \& Jandrić, 2018). However, despite the rapid digitalization of the learning process, education remains away from the post-digital reality in which it is carried out. Our survey showed a paradoxical state of affairs: two basic components are needed for the technical implementation of distance learning: stable Internet and technical equipment. It would seem that this issue has been resolved in modern realities, when everyone has a smartphone, and almost everyone has a computer and access to the Internet. However, the material and technical base of the respondents turned out to be not fully adapted for the training purposes. Teachers and students were not sufficiently equipped with the necessary technology to conduct distance learning, and the servers and educational platforms could hardly withstand the influx of students. The respondents noted that they faced with the following difficulties: "ruffled screen, crackled sound, no image, files impossible to read or send". Thus, considering digital technologies as their future, even being in the process of visible digitalization, higher education turns out to be away from the post-digital reality of a particular student. As in the traditional learning model, the student is placed in the background. Under the guise of complete digital freedom of learning, the real student with his/her needs and 
material, technical conditions is almost wholly ignored. The things declared as freedom of digital learning turns out to be indifference to whoever sits in front of a monitor screen and consumes a digital learning product.

This, in turn, poses another problem - additional financial costs. Here we are faced with the fact that not everyone has the financial ability to make extra spending, for example, to acquire high-quality equipment that would meet all the requirements of the educational process in the context of distance learning. This is reflected in the quality of the educational process and its accessibility, as well. This is the paradox: distance learning is associated and positioned as education accessible to everyone, regardless of material well-being, time and place, age and training. In reality, the availability of digital learning is severely limited.

Another example of ignorance of the student is the problem of time and place of online learning. It seems that, unlike a classic classroom lesson, distance learning is not tied to a place and time. Nevertheless, our respondents were faced with the problem of lack of personal space and everyday difficulties. For example, the students living in dormitories or in small apartments with other family members faced the lack of an organized workplace and study environment with participating in lectures and seminars, as well as doing homework. This situation shows that such difficulties are acceptable in the emergency conditions of the transition to distance learning within the framework of the self-isolation regime when citizens were to stay in their homes, and all public places were closed. However, these problems will remain with students in online education after the end of the pandemic; they will have to organize their own learning environment.

A more significant problem that appears within the implementation of online learning is the deterioration in the health and well-being of students. It can also be seen as a consequence of ignoring the student when using digital distance learning technologies. Thus, due to the increased time spent at the smartphone or laptop screen in a sitting position, the respondents began to note the appearance of headaches, pain in the back and neck, eye fatigue, as well as a stressful emotional and mental state. According to the Order of the Ministry of Education and Science of the Russian Federation No. 816 dated August 23, 2017, "organizations independently determine the ratio of the volume of classes conducted by direct interaction of a teacher with a student, including using e-learning, distance learning technologies" (Order of the Ministry of Education and Science of the Russian Federation No. 816 dated August 23, 2017). Due to the uncertain situation that arose in connection with the introduction of the self-isolation regime, as well as the transition to distance learning, the universities, so as not to be accused of losing academic hours, conducted lectures and practical classes in full. A standard school day includes 3-4 pairs of 90 minutes for a total of 4-6 hours. If we add to this time the time spent doing homework, which was also carried out only using gadgets within the framework of distance learning, due to the impossibility of transferring it to the teacher in another way, then the student spent about 10 hours a day at the screen on average, which entailed health problems.

\section{Summary}

The survey results of students who studied during the COVID-19 pandemic using distance digital forms show that financial and technical difficulties, health problems, as well as problems of place and time of participation in online classes, can be distinguished among the difficulties they faced. All these problems demonstrate that digital technologies are not able to solve the internal contradictions of higher education. The inclination to impose such a digitalization mission rather distracts from solving significant problems of the process and teaching methods, since a new digital copy is offered instead of solving them.

\section{Conclusions}

The pandemic and the forced transition to distance learning using digital technologies made the recognition of post-digital reality inevitable. If, before the COVID-19 pandemic, it was still possible to nurture hopes for the perfection of the future of digital education, now it has become clear that we live in a world shaped by the digital revolution, and that this cannot solve the inherent problems of higher education. The pandemic has forced people to look at the problems of higher education without hiding behind a utopian dream of a digital future.

\section{Acknowledgements}

The work is performed according to the Russian Government Program of Competitive Growth of Kazan Federal University. 


\section{References}

Biesta, G. (2016). The Rediscovery of Teaching: On robot vacuum cleaners, non-egological education and the limits of the hermeneutical world view, Educational Philosophy and Theory, 48(4), 374-392. https://doi.org/10.1080/00131857.2015.1041442

Cramer, F. (2015). What is 'post-digital'? In D. M. Berry \& M. Dieter (Eds.), Postdigital aesthetics: Art, computation and design (pp. 12-26). New York, NY: Palgrave Macmillan. https://doi.org/10.1057/9781137437204_2

Jandrić, P., Knox, J., Besley, T., Ryberg, T., Suoranta, J., \& Hayes, S. (2018). Postdigital science and education. Educational Philosophy and Theory, 59(10), 893-899. https://doi.org/10.1080/00131857.2018.1454000

Kuzmina, I. We Teach Better Than in the USA: HSE Rector Yaroslav Kuzminov on the revolution in higher education, universities for the elite and the pandemic results // Forbes Financial and Economic Journal. 2020. Retrieved

from https://www.forbes.ru/biznes/403155-my-uchim-luchshe-chem-v-ssha-rektor-vshe-o-revolyucii-v-vysshem-obra zovanii-vuzah-dlya

Murphy, P. (2013). Beautiful Minds and Ugly Buildings. In: Peters M.A., Besley T. (Eds) The Creative University. Creative Education. (pp. 33-41). SensePublishers, Rotterdam. https://doi.org/10.1007/978-94-6209-245-7_3

Octaberlina, L. R., \& Muslimin, A. I. (2020). EFL Students Perspective towards Online Learning Barriers and Alternatives Using Moodle/Google Classroom during COVID-19 Pandemic. International Journal of Higher Education, 9(6). https://doi.org/10.5430/ijhe.v9n6p1

Order of the Ministry of Education and Science of the Russian Federation No. 816 dated August 23, 2017 "On Approval of the Application Procedure for E-Learning, Distance Learning Technologies by Organizations Engaged in the Educational Activities in the Implementation of Educational Programs". Retrieved from http://ivo.garant.ru/\#\%2Fdocument\%2F71770012\%2Fparagraph\%2F1\%3A0

Peters, M. A., \& Jandrić, P. (2018). (n. d.). The Digital University Manifesto. In The Digital University. Bern, Switzerland. https://doi.org/10.3726/b11314

Peters, M. A. (2017). Technological unemployment: Educating for the fourth industrial revolution. Educational Philosophy and Theory, 49(1), 1-6. https://doi.org/10.1080/00131857.2016.1177412

Saser, O. B., \& Makhasane, S. D. (2020). Global Perceptions of Faculties on Virtual Programme Delivery and Assessment in Higher Education Institutions During the 2020 COVID-19 Pandemic. International Journal of Higher Education, 9(5). https://doi.org/10.5430/ijhe.v9n5p181

Schwab, K. (2016). The fourth industrial revolution, Davos 2016. Retrieved from http://www.weforum.org/agenda/2016/01/the-fourth-industrial-revolution-what-it-means-and-how-to-respond

Stachiw, A. (2014). MOOCs and the Democratization of Online Education. Retrieved from https://truthout.org/articles/moocs-and-the-democratization-of-online-education/

\section{Copyrights}

Copyright for this article is retained by the author(s), with first publication rights granted to the journal.

This is an open-access article distributed under the terms and conditions of the Creative Commons Attribution license (http://creativecommons.org/licenses/by/4.0/). 